\title{
"Chuva, como te queremos!": representações sociais da água através dos desenhos de crianças pertencentes a uma região rural semiárida do México
}

\author{
"Rain, we need you so much!": social representations \\ of water based on drawings of children \\ from a semiarid region of Mexico
}

\author{
Maria Luiza Schwarz ${ }^{1}$. Thora Martina Herrmann ${ }^{2}$. \\ Maria Costanza Torri ${ }^{3}$. Luciane Goldberg ${ }^{4}$
}

\begin{abstract}
Resumo: Desenhos infantis são instrumentos muito importantes na análise dos conhecimentos e valores sobre os recursos naturais, como a água, que é um recurso essencial para a vida humana. Este trabalho avalia desenhos de crianças e adolescentes da comunidade rural de Francisco Medrano-México. O enunciado de chamada para a atividade foi: "Desenhe tudo que lhe vem em mente quando falamos em água". Após a execução, houve diálogos sobre o problema entre estudantes, professores e pesquisadores e a exposição dos trabalhos em sala de aula. Em seguida, fez-se um exame detalhado sobre o contexto dessas obras, qual foi a mensagem que a criança quis transmitir quando a palavra "água" lhe veio em mente. O estudo revela que muitos conhecimentos dos jovens sobre a água podem fluir através do desenho e que este é instrumento muito importante na construção de Temas Geradores, na perspectiva freiriana.
\end{abstract}

Palavras chave: Água. Chuva. Desenho infantil. Meio ambiente. Educação ambiental. México.

\begin{abstract}
Children's drawings are very important tools to assess the values that they attribute to the environment and natural resources; this is especially the case for water, which is an essential resource for human life. This study analyzes drawings of children and adolescents from the rural community of Francisco Medrano-Mexico. The task set for the students was: "Draw anything that comes to your mind when you hear the word 'water"'. After the students finished their task, discussions took place among students, teachers and researchers about the different meanings attributed to the drawings. For the analysis of the drawings, first we classified the elements represented, subsequently, we proceeded with a detailed examination of the context of the drawings. This study reveals that drawings can provide insight on how young people see the water and that drawing can be very important tools in building theme generators in a Freirean perspective.
\end{abstract}

Keywords: Water. Rain. Children drawning. Environment. Environmental education. Mexico.

\footnotetext{
${ }^{1}$ Universidade da Região de Joinville (Univille), Programa de Pós-graduação em Patrimônio Cultural e Sociedade, Joinville, SC, Brasil. E-mail: <luizaschwarz@hotmail.com>.

${ }^{2}$ Université de Montréal, Quebec, Canada.

${ }^{3}$ University of New Brunswick, Fredericton, Canada.

${ }^{4}$ Universidade Federal do Ceará (UFC), Faculdade de Educação, Fortaleza, CE, Brasil.
} 


\section{Água, patrimônio universal da humanidade: representada, desejada e indispensável para todas as formas de vida do planeta}

A água é essencial tanto para a humanidade como para toda a biodiversidade. É impossível pensar na vida sem água, pois ela traz vida para as áreas urbanas e rurais e são vários os valores associados a esse recurso natural, como valores utilitários, naturalistas e estéticos (REBOUÇAS, 1997).

Uma grande quantidade de água pode causar desastres naturais, como inundações e deslizamentos de terra, enquanto a sua falta pode causar secas desastrosas. Este último fenômeno está cada vez mais ligado às mudanças climáticas (MARTINS, 2009). Regiões caracterizadas por clima semiárido sofrem de escassez de água durante vários meses por ano, o que afeta a cultura, os meios de vida e os processos de migração das populações. Se olharmos para o papel que a água desempenha em várias culturas humanas, podemos ver que está bastante presente na arte, na literatura, na música, na filosofia e na política (FORTES, 2007).

A maneira que esse recurso é utilizado provoca sua degradação e coloca em risco a própria existência da humanidade. Segundo a ONU, quase metade das áreas cobertas por água doce não existe mais. $\mathrm{Na}$ atualidade, a água representa/significa mais que uma fonte de vida, ela está se convertendo em uma fonte de conflitos, uma guerra de poderes, uma luta pela sobrevivência e uma fonte de riqueza. A falta de acesso a esse recurso gera desigualdades, pobreza e injustiça social, como também diferenças entre os países mais e menos desenvolvidos, pois limita o crescimento e o bem estar da população (RAMIREZ; YEPES, 2011).

Hoje, os organismos internacionais, como o Centre Tricontinental (2001) e o Comitê Promotor Mundial para o Contrato da Água (1998) consideram a água Patrimônio Universal da Humanidade, de direito internacional, sendo o seu uso indiscriminado/desperdício, um problema ético. Barros e Amin (2008) designam a água como um Patrimônio Comum da Humanidade, um recurso de toda nação que dele dispõe. Patrimônio Comum, Patrimônio Universal, Bem Comum dos Povos, Fonte de Vida, Ouro Azul, a água ocupa um lugar central dentro dos debates que dizem respeito ao futuro da humanidade e do abastecimento aos povos que está em perigo, sendo que a sua gestão gera inúmeros conflitos. Discute-se a legitimidade na entrega desse recurso, um patrimônio coletivo, a companhias privadas (CARDOSO, 2006).

Mas nem sempre a água foi um objeto de conflito; antes, ela foi tratada como patrimônio comum, quase sempre cuidada com desvelo pela população rural e a sua utilização se dava em forma de partilha (GALIZONI; RIBEIRO, 2011). A água faz parte de uma imagem mental que é produzida durante toda a história da humanidade. Os estudos da dimensão simbólica da água têm ressaltado basicamente três aspectos: a água como fonte de vida, a água como meio de purificação e a água como centro de regeneração (BRUNI, 1993).

Esta pesquisa tem o interesse de verificar quais são as representações sociais da água para as crianças residentes no campo de uma região semiárida mexicana e se apoia na ideia de que essas crianças são cidadãs e, como tais, possuem o direito de voz, ainda mais quando se trata de uma temática tão importante para suas vidas, como a água e toda a sua dimensão simbólica. A Teoria das Representações Sociais teve início nos anos de 1960, com os trabalhos de Serge Moscovici, mas a origem do conceito teve como base a Sociologia, de Durkheim, a Antropologia de Lévy-Bhrul, a teoria da linguagem, de Saussure, os estudos sobre as representações infantis de Piaget e a teoria do desenvolvimento cultural, de Vigotsky (JOVCHELOVITCH, 
1998; OLIVEIRA; WERBA, 1998; RIBEIRO; PINTO JÚNIOR, 2009). Durkheim falava em representações coletivas, o que Moscovici mudou para representações sociais, pois o segundo se adapta ao mundo mais complexo e repleto de bruscas mudanças sociais, políticas e econômicas (JOVCHELOVITCH, 1998).

A Teoria das Representações Sociais permite refletir sobre o objeto, deixando algo que não era conhecido, familiarizado. O indivíduo necessita refletir sobre o mesmo, por esta razão é bastante cognitiva, e é a combinação de antigos componentes com novos, que são incrementados, modificados, dando uma continuidade na produção de imagens e ideias. A representação social não é estática, ela sofre constantes modificações. As representações são os filtros interpretativos da realidade, servem como meios normativos de orientação dos comportamentos individuais e sociais e constituem um dos elementos chave da articulação do homem/meio ambiente. Por esta razão o interesse de estudar esta maneira de conhecimento, assim como na dinâmica e no processo (DE VANSSAY, 2003).

A forma mais comum de apreender as representações é através das técnicas verbais, podendo ser utilizados os questionários, as associações livres ou o desenho (SPINK, 1993). Os desenhos infantis desempenham um papel importante na construção das representações sociais, ele sempre foi utilizado pelos humanos como forma de representar pensamentos, sentimentos e ações (SILVA, 2010). O simbolismo do desenho permite a comunicação desde épocas bastante precoces da vida do homem, antes até da fala e da escrita (HAMMER, 1981). Dessa maneira, o desenho infantil se constitui uma das primeiras formas de expressão. Os desenhos são utilizados como instrumentos nas pesquisas sobre o desenvolvimento da inteligência, da cognição, das habilidades motoras e afetivas, bem como no ambiente social e cultural das crianças (GRUBITS, 2003).

O uso de desenhos em estudos que analisam a relação entre criança/ambiente/recursos naturais e compreensão de outros conceitos científicos ainda é muito limitado, apesar da sua importância e da sua eficácia. Todavia, é bastante utilizado na psicologia clínica. A linguagem do desenho se desenvolve natural e espontaneamente para a maior parte das crianças. Estudos mostram que a grande maioria delas, independentemente da sua origem, começou a se expressar através da utilização do desenho, de maneira espontânea, a partir de um ano de idade (KELLOGG, 1970). O desenvolvimento do desenho mais elaborado ocorre gradualmente com o avançar da idade, revelando, em cada caso, uma nova maneira de perceber e representar a realidade.

O desenho é um instrumento muito útil para analisar as informações sobre o que a criança vê, sente e pensa sobre o mundo (CHANG, 2005; GARRIDO; MEIRELLES, 2014; KATZ, 1998; PEDRINI; COSTA; GHILARDI, 2010; PROFICE et al., 2013; SCHWARZ; SEVEGNANI; ANDRÉ, 2007). Um bom exemplo para ilustrar esse argumento são os desenhos feitos pelas crianças brasileiras, que vividamente representam a Mata Atlântica em região de morros e serras no sul do Brasil. A cor verde predomina em todos os desenhos (SCHWARZ, 2007) e justamente nas regiões mais altas, onde é a realidade vivenciada por essas crianças. Assim, os desenhos mostram uma compreensão do mundo pela criança: como Chang (2005, p. 105, tradução nossa) afirma “[...] uma imagem vale mais que mil palavras".

O estudo das representações sobre a água, através dos desenhos, pode fornecer pistas interessantes para programas educacionais de tomada de consciência sobre a conservação desse recurso entre os jovens que vivem em lugares onde a água é escassa, bem como para aqueles 
que vivem onde há certa abundância, mas que a desperdiçam, deliberadamente. Também é importante que se compreenda os anseios das crianças que necessitam de um abastecimento efetivo de água potável para o consumo e para as práticas primordiais da vida cotidiana, como beber, preparar seus alimentos, lavar-se, lavar louças e roupas, para que haja certa solidariedade entre os países ricos com os lugares desprovidos, uma vez que riqueza está diretamente ligada à abundância dos recursos naturais. Além disso, uma melhor compreensão das representações das crianças sobre o sistema ecológico da água, sobre o que ela sabe a respeito da formação dos rios e dos recursos hídricos é crucial para ampliar a literatura acadêmica em Geografia, Ciências e Educação Ambiental sobre esse precioso recurso dentro de um contexto e não apenas de maneira isolada.

As Representações Sociais acerca da água emergem das experiências cotidianas. Por essa razão, podem servir como subsídios para estudos sob a perspectiva da Abordagem Temática freiriana, baseada nas concepções de Educação Libertadora de Freire (1994) e em que a problematização de situações reais que emergem das contradições sociais vivenciadas e dos limites explicativos estão presentes nas falas dos indivíduos (FREIRE, 1994). O Tema Gerador baseia-se, segundo Freire (1994), em três momentos: (i) Investigação da Temática através do universo vocabular e do estudo dos modos de vida na localidade (Estudo da Realidade); (ii) Através da seleção de temas e palavras geradoras - realiza-se a codificação e decodificação desses temas buscando o seu significado social, ou seja, a consciência do vivido. A codificação acontece neste momento, que pode ser expressa por meio de pinturas, fotografia ou escrita. $\mathrm{Na}$ descodificação, que é um processo dialético, os integrantes da comunidade escolar se reconhecem como transformadores do mundo; (iii) Problematização - problematizar o conhecimento já construído pelo aluno, aguçando as contradições e localizando as limitações desse conhecimento, propiciando alternativas de apreensão do conhecimento científico (FREIRE, 1994).

As representações sociais da água através dos desenhos são o conhecimento de saberes existentes, mesmo que não percebidos como saberes. É o caminho metodológico pretendido no processo de conscientização, na discussão dos conteúdos da "consciência ingênua" do mundo e das coisas em busca da "consciência crítica" para dar um significado à educação. Este artigo tem por objetivo verificar os "conhecimentos ingênuos" representados nos desenhos dos jovens mexicanos da região de Francisco Medrano. em busca de pré-temas geradores sobre a água, que podem ser aplicados em diversas disciplinas, como Ciências, Educação Ambiental e Geografia, para que norteiem diretivas para o programa curricular e programas para a sala de aula na localidade estudada e, até mesmo, em outras localidades que vivem o mesmo problema da seca e da escassez desse recurso natural.

Muitos problemas ambientais surgem devido a uma falta de diálogo entre as diferentes partes interessadas e a falta de compreensão do funcionamento do ecossistema local. As representações sociais são essenciais para planejar programas educacionais eficazes que visem à conscientização sobre a importância de proteger os recursos hídricos (FÉLONNEAU, 2003), entre outros recursos. O estudo das representações socioculturais dos estudantes apresenta uma boa oportunidade de melhor explorar as ações educativas mais adequadas, que seguem a Abordagem Temática Freiriana, no que diz respeito ao desenvolvimento de um modelo de ensino que priorize a importância e a necessidade da conservação da água, indo ao encontro dos anseios dos jovens, pois a problematização significa um processo no qual o aluno é instigado a confrontar situações do seu cotidiano, desestruturando o seu conhecimento prévio sobre o 
assunto e fazendo-o construir novos saberes acerca das questões abordadas. Dessa maneira, este artigo evoca as seguintes questões:

- O que vem primeiramente à mente das crianças, quando são estimuladas para desenhar água?

- Como as crianças representam os sistemas naturais e os construídos para o abastecimento de água na região?

- Qual é o padrão ideal de consumo de água, segundo as crianças?

\section{Área de Estudo}

A aldeia de Francisco Medrano pertence à área rural do município de Tula, que está localizada no Sudoeste de Tamaulipas $\left(22^{\circ} 0^{\prime} 0^{\prime \prime} \mathrm{N}, 99^{\circ} 0^{\prime} 0^{\prime \prime} \mathrm{W}\right)$, um dos 31 estados do México. A aldeia é rodeada por vegetação xerophyllous, que representada principalmente por plantas cactáceas e outras plantas com um ritmo lento de crescimento, com um ciclo de vida longo e longos períodos reprodutivos. Muitas espécies ameaçadas são encontradas nesse tipo de ecossistema (GONZÁLEZ-MEDRANO, 1993).

A topografia de Tamaulipas é caracterizada principalmente por colinas de baixa altitude e por planícies na região banhada pelo Golfo do México. As maiores elevações são encontradas na Sierra Madre Oriental, a Sierra de San Carlos e da Serra de Tamaulipas, com altitudes que podem chegar a $2000 \mathrm{~m}$. As partes do sul e sudeste do estado têm um clima úmido e semiúmido, com uma estação chuvosa no verão. O resto do estado, que representa quase 90\% do território, incluindo a área onde foi realizado nosso estudo, apresenta um clima árido. A topografia e as exigências climáticas são as principais características que determinam a diversidade da vegetação e da distribuição da vegetação no estado (MÉXICO, 2015).

A população total de Francisco Medrano é de 119 habitantes. As temperaturas variam de $43^{\circ} \mathrm{C}$ (no máximo) a $0^{\circ} \mathrm{C}$ (no mínimo). As chuvas ocorrem entre maio e agosto, seguidas por um longo período de falta de precipitações. Durante a pesquisa de campo, foi observado que apenas os habitantes com um pouco mais de dinheiro podiam se dar ao luxo de comprar água e armazená-la em grandes recipientes de plástico, enquanto que a maioria da população local deve caminhar vários quilômetros até a Sierra Madre Oriental para conseguir água potável.

A economia da região baseia-se na cultura de Lechuguilla (Agave lechegnilla), uma planta fibrosa. Outras formas de atividades econômicas são representadas pelo comércio de madeira que é vendida na cidade de Tula, e por várias pequenas indústrias de cosméticos, que usam as plantas locais como matéria-prima. Esses produtos são conhecidos apenas localmente e têm uma comercialização muito limitada fora de Tula. O município possui contrastes sociais marcados, sendo que a maioria dos habitantes vive numa acentuada pobreza, e alguns membros da sociedade estão estabilizados socialmente. Em 2011, o governo de Tamaulipas priorizou 42 metas para o Estado, dentre as quais o abastecimento de água é a principal. Francisco Medrano, além do abastecimento de água, tem como segunda meta do governo, o melhoramento das habitações. A maioria das casas não possui banheiro (PLAN..., 2011).

O Estado de Tamaulipas possui uma economia baseada na agricultura, e as famílias estão envolvidas, principalmente, na criação de gado, de cabras e outros animais, como porcos e galinhas. Muitas vezes, essas atividades são somente para a subsistência. A migração para os 
EUA é particularmente alta nesta área, embora estejam cientes das dificuldades de um imigrante neste país.

\section{Procedimentos}

O interesse desta pesquisa é de avaliar os valores e os conhecimentos ingênuos das crianças sobre a água ${ }^{5}$, seguindo, assim, um método de pesquisa baseado nas representações sociais com uma abordagem qualitativa, embora muitos dados tenham sido quantificados. A investigação das representações sociais das crianças sobre a água foram realizadas com os estudantes da única escola dessa comunidade rural. A população-alvo foi representada por 29 estudantes com idade entre 6-14 anos que frequentaram a escola primária, sendo 13 meninas e 16 meninos. Estes representavam a população total de crianças que frequenta a escola. Solicitamos os desenhos através da seguinte frase: "desenhe tudo que lhe vem em mente quando falamos a palavra 'água"'. Não foi analisada a qualidade gráfica dos desenhos, mas sim o contexto e os elementos que os desenhos apresentaram. No verso de cada desenho, foi escrita uma explicação, a fim de compreender o contexto do desenho e os elementos representados, servindo, também, como unidade de análise sobre as representações da água.

Todos os estudantes foram convidados a desenhar e receberam vinte e quatro cores de lápis de cor e papel branco, formato A4. O tempo dado para fazer os desenhos foi de 60 minutos. Não houve discussão antes da sessão, para não influenciar as representações pré-concebidas dos jovens acerca da água e ajudar na análise de contradições sociais vivenciadas pelos envolvidos (FREIRE, 2008). As discussões vieram depois, no término dos desenhos, juntamente com as pesquisadoras e o professor. As histórias que contavam sobre a luta na busca desse recurso,

\footnotetext{
${ }^{5}$ Estávamos em Francisco Medrano de passagem para realizar uma pesquisa sobre uma cooperativa de mulheres que fabricavam xampus com plantas medicinais nativas da região. Quando as crianças, que eram filhos destas senhoras nos viram, ficaram fascinados e curiosos. Falaram para seus professores, e eles também ficaram curiosos e prontos para aproveitar esta experiência da nossa estadia na região, em sala de aula. Evidentemente, nos convidaram para conhecer a escola, conversar com os estudantes, explicar nosso trabalho, falar dos nossos países, o que estávamos fazendo por ali, naquela pacata comunidade rural, com uma única escola primária. A escola era pequena, mas bem organizada, bem cuidada, com dois professores que visivelmente amavam estar ali. Tudo era feito por eles: o pomar, o jardim, as coleções de plantas, de rochas. A escola, na época, contava com 29 estudantes e dois professores. Todos os estudantes distribuídos em duas salas de aula: os “pequenos", de 6 a 9 anos, em uma. e os "grandes". de 10 a 14. em outra. Os professores da referida escola, estavam preocupados com o conhecimento dos jovens sobre a água e nos fizeram um pedido: "gostaríamos muito de saber quais são os conhecimentos dos jovens para com a água, de maneira geral. Vocês poderiam nos ajudar? Aqui a água é escassa, e muitos destes jovens frequentam a escola para poder usufruir do recurso, pois estão há meses sem ela. Muitos adoecem; nestes dias, faltam aula. Sei que a visão de vocês será muito útil para nossa comunidade, vocês possuem este olhar externo, de alguém que não passa pelos mesmos problemas. Vocês poderiam nos ajudar a mobilizar os governantes, na busca de políticas públicas sobre a água na região. Muitas vezes, o olhar externo é melhor recebido". Foi neste momento que surgiu a ideia de solicitar os desenhos e aproveitar nossa experiência sobre a análise e a eficácia dos mesmos. Afinal, o tempo era curto para uma pesquisa mais intensa. Seguimos as normas éticas da Université de Montréal, com a qual estávamos vinculadas, e as trocas foram riquíssimas para ambos os envolvidos.
} 
das longas caminhadas até o "pé da serra", da alegria de poder ir até a escola e encontrar, além dos amigos e dos professores, a água nas torneiras. A evocação levou-os a querer conversar sobre o tema e é claro que foi uma atividade pedagógica muito rica! A palavra água foi utilizada como uma "palavra problematizadora", porque a problematização aqui não é uma atividade vazia, ela possui um significado político, uma discussão conscientizadora da realidade vivida, da realidade opressora das sociedades desiguais e vulneráveis. O estudo da realidade não se limita, simplesmente, à coleta de dados, mas deve, acima de tudo, perceber como as crianças percebem sua própria realidade (ANTUNES, 19-- ?) .

Os elementos gráficos presentes no desenho foram analisados, seguindo cinco parâmetros: (1) frequência dos elementos desenhados (chuva, nuvens, animais, plantas, etc.); (2) a água para as atividades domésticas; (3) a água nas atividades recreativas; (4) o abastecimento de água e sua importância para animais e plantas; e (5) o padrão de consumo ideal na minha casa.

Para definir a média de elementos representados, foram realizados dois testes: um teste de frequência de elementos desenhados e um teste de média simples, sendo que o total de elementos foi dividido pelo número de participantes. As informações codificadas compreendem os seguintes elementos: chuva, rio, nuvem, sol, biodiversidade, incluindo as plantas e os animais. A presença humana foi classificada separadamente.

\section{Resultados e discussão}

\section{Elementos representados e classificados em temas}

As crianças da comunidade Francisco Medrano representaram um total de 156 elementos, com uma média de 5.3 itens para cada criança. A chuva é o principal elemento ilustrado. $\mathrm{Na}$ verdade, a chuva está presente em 21 (74\%) dos 29 desenhos, juntamente com rios (74\%) e nuvens $(73 \%)$. A ênfase que as crianças deram a esses componentes está relacionada à sua importância para eles. A reação emocional que possuem através da precipitação é viva e intensa em muitos desses desenhos: a chuva é representada de forma colorida, com gotas enormes, que expressam um sentimento de alegria e otimismo, refletindo a expectativa bastante desejada sobre esse fenômeno meteorológico. A cor e o tamanho das gotículas ilustram um estado emocional típico de crianças com idade inferior a 10 anos: na verdade, o que é mais importante e significativo ganha tamanho e proporções enormes em suas representações (Figuras 1A e 1B).

Quando se pede para que uma criança desenhe uma paisagem local, o número de elementos representados pode refletir a biodiversidade local e o nível de conhecimento que ela tem do meio natural, da presença da biodiversidade e dos recursos naturais. O desenvolvimento da percepção e, consequentemente, a representação dos elementos da paisagem natural por uma criança é o resultado de sua interação com o ambiente. Essa interação pode ser estimulada e reforçada por meio de atividades educacionais na escola e na família (GOLDBERG; YUNES; FREITAS, 2005). O desenho de uma criança, independentemente de sua idade, revela o que de mais importante ela aprendeu e experimentou de seu ambiente local, bem como os elementos que são mais significativos para sua vida, como a utilização e a cognição em geral para com a água. Este é, especialmente, o caso de uma comunidade localizada em uma região semiárida, caracterizada por longos períodos com falta do recurso. 
Alguns desenhos refletem a abundância de grandes rios que são abastecidos por grandes gotas de chuva, a nascente dos rios é frequentemente representada nas montanhas, que também revelam a presença de vários afluentes (Figura $2 \mathrm{~A}$ ). As nuvens estão associadas a essas precipitações muito abundantes (12,8\% - N =20) (Figura 1A). Os seres humanos estão presentes em $9 \%$ dos desenhos $(7,1 \%-\mathrm{N}=12)$ (Figura 1B; 3A). Nesses casos, os estudantes retrataram-se durante a realização de atividades relacionadas, como indo buscar de água, dando água para os animais ou no envolvimento com atividades recreativas aquáticas. Poucos elementos construídos com o intuito de fazer reservas de água durante o período das chuvas foram desenhados. O conhecimento tradicional, como a sabedoria asteca e maia do armazenamento da água da chuva, não foi retratada nessas representações.

A biodiversidade específica local é representada principalmente por árvores e flores. Surpreendentemente, apenas algumas crianças retrataram cactos, plantas que estão onipresentes no ecossistema local. Isso pode estar relacionado à falta de apego à essas espécies e às paisagens locais. Geralmente, os cactos são espécies que machucam e causam medo. Por essa razão, na maioria dos desenhos, elas retrataram árvores de grande porte e sem espinhos. Outra razão para a não representação de cactos pode estar ligada ao fato de que as cactáceas, aparentemente, não necessitam de muita água para sobreviver, ao contrário de outras árvores e flores, que são verdes ou em flor num determinado período do ano, quando as chuvas são mais frequentes. Outra questão importante que emerge dos desenhos é que as crianças desenham o que é mais importante para a vida cotidiana, como na relação da água para a utilização em família e para os animais.

Figura 1. A chuva nas representações
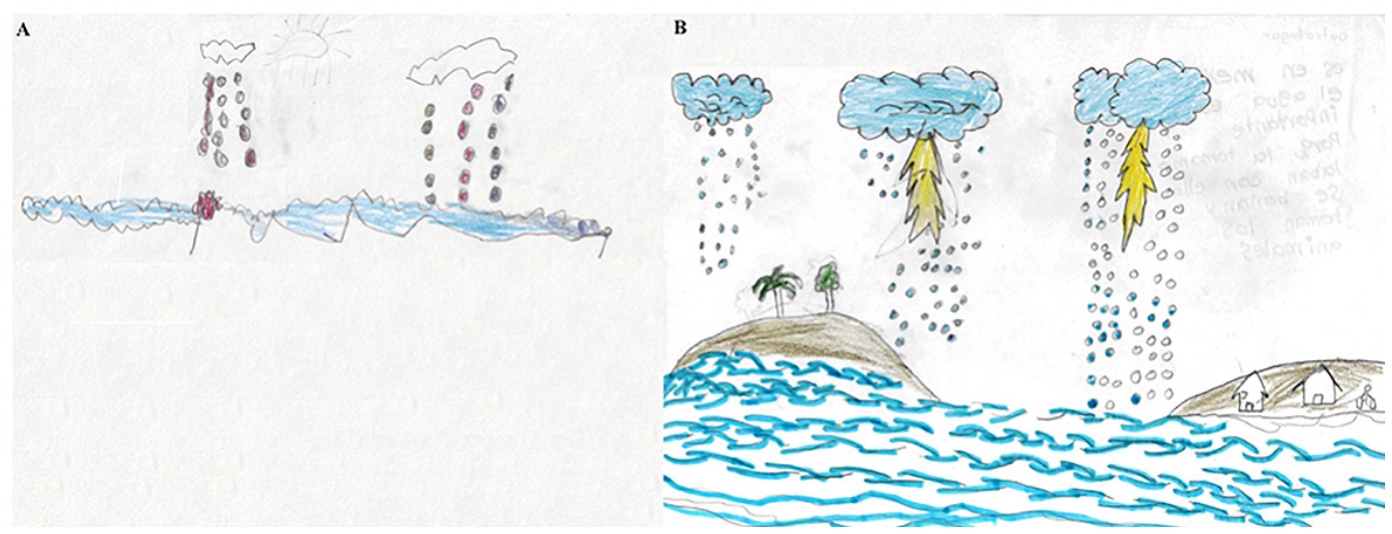

A) desenho de uma menina de seis anos: pingos de chuva enormes (nenhuma explicação na parte de trás).

B) desenho de um menino de 10 anos: gotas enormes, água abundante nos rios. A presença humana na tarefa de buscar água. A explicação na parte de trás do desenho: "Essa paisagem é no México, onde a água é importante para nós e para os animais, pois é necessária para beber e para tomar banho".

Fonte: desenhos elaborados pelos estudantes. 
A maioria dos desenhos contém, como elemento principal, a chuva, os rios e as nuvens, e possuem pequenas diferenças, segundo a idade: as crianças com idade entre 6-9 anos desenharam, com maior frequência, os rios, as nuvens, a chuva e a presença humana. O número médio de elementos representados por esse grupo de idade foi de 4,6 elementos. Ruíz Pérez e Fernández Crispín (2008) também observaram a presença humana com maior intensidade nos desenhos de crianças da pré-escola (4 a 6 anos), no Município de Puebla, no México. Os autores ainda observaram uma maior presença de humanos nos desenhos da população indígena.

Estudantes pré-adolescentes, com idade entre 10-14 anos, desenharam, com maior frequência, outros elementos, como montanhas, cachoeiras, poços, tanques de água, etc. Além disso, retrataram, com maior importância, a biodiversidade, como pássaros, árvores, flores etc., obtendo uma média de 7,7 elementos desenhados. O aumento do número de elementos desenhados pelos estudantes, bem como a diversidade, estão, provavelmente, relacionados com a sua capacidade de desenhar, que progride com a idade e é obtida progressivamente através dos estágios de desenvolvimento intelectual, como descrito por Luquet (1927). O autor descreve essa progressão através de seus estudos, citando que a partir de 9 anos até 11 anos de idade, uma criança se esforça para fazer representações com perspectiva, profundidade, formas, tentando representar os movimentos e sua ideia de tempo. Após essa fase (12 a 13 anos), há geralmente um declínio da representação gráfica entre as crianças. Essa progressão também foi vista nos trabalhos de Profice et al. (2013), quando as crianças representaram a Mata Atlântica, e nos trabalhos de Schwarz, Sevegnani e André (2007).

Profice et al. (2013) explicam que a familiaridade com a região e com as espécies a serem representadas também pode aumentar o número de elementos desenhados, além do aumento natural, através da idade. A representação dos elementos que vivenciam cotidianamente, de maneira consensual e informal, é indispensável para a vida humana (ARRUDA, 2002), assim como representar através do universo reificado, que é cristalizado no conhecimento científico com linguagem e classificações próprias. Ambas se complementam e não existe uma hierarquia entre o universo de representações consensuais e reificadas (ARRUDA, 2002).

Crianças com idade entre 10 anos e mais velhos muitas vezes, tentam ajustar seus desenhos para o que veem, esforçando-se para uma representação mais realista (LOWENFELD, 1977). O nível de percepção e observação aumenta, assim como a necessidade de detalhes de representação. O declínio da representação gráfica é produzido pela dificuldade técnica de desenhar "corretamente", no que diz respeito à forma, cor, textura, perspectiva, proporção, luz e sombra, etc. A criança, nessa idade, torna-se cada vez mais exigente com relação às representações "realistas" e, sem o apoio de alguém para ensiná-la a resolver problemas técnicos de representação, a criança pode parar de desenhar, o que pode levá-la ao bloqueio da capacidade de se expressar através do desenho (GOLDBERG; YUNES; FREITAS, 2005).

O sol, o rio, as nuvens, a presença humana, a chuva, a biodiversidade e muitos outros elementos foram revelados através dos desenhos e classificados segundo a idade e o gênero. As meninas representam, com maior frequência, os elementos diretamente relacionados à biodiversidade, que são geralmente as flores regadas pela chuva. A chuva e os rios também foram representados repetidamente. Os desenhos dos meninos tiveram diferentes elementos retratados, como barcos, lagos ou represas, e também incluiram um maior número de ocorrência dos seres humanos. Cinco desenhos dos meninos mostraram atividades recreativas relacionadas com a água, como a vela. Meninas não representam essas atividades. Se existe uma presença 
humana, é frequentemente associada às tarefas domésticas, tais como buscar a água no rio, atividade presente em três desenhos (Figura 3A). Pode-se explicar essas diferenças através do fato de que os meninos, geralmente, desfrutam de uma maior liberdade para vivenciar momentos fora de casa e de envolverem-se em atividades ao ar livre, em contato direto com a natureza. Geralmente, os pais protegem mais as meninas contra os possíveis perigos. Além disso, na cultura mexicana, são os homens os responsáveis pelo pastoreio dos animais e das atividades agrícolas, enquanto as mulheres se encarregam das tarefas domésticas. O abastecimento de água é responsabilidade das mulheres e das crianças. Como consequência, meninos e meninas adotam comportamentos distintos em relação ao ambiente e aos recursos naturais, e isso está bastante presente nos desenhos, embora as diferenças não sejam relevantes. $\mathrm{Na}$ pesquisa realizada por Ruíz Pérez e Fernandéz Crispín (2008), os meninos, principalmente os indígenas, desenharam uma maior quantidade de outros elementos diversos, como: piscinas, barcos, garrafas, reservatórios, bandejas, jarras, pias, torneiras, tanques, poços, regadores, copos, escova e creme dental, etc. Notamos a maior diversidade de elementos nos desenhos das crianças de Puebla e fica evidente que essas crianças mexicanas são oriundas de áreas maiores e mais urbanizadas.

Figura 2. Desenhos e elementos representados

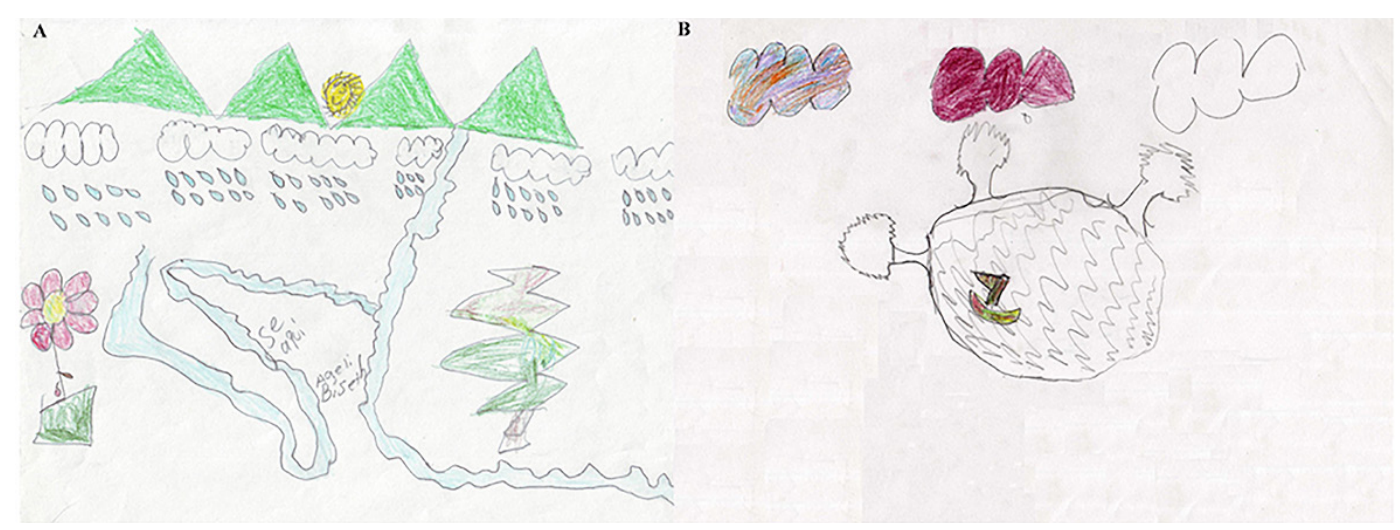

A) desenho de uma menina de oito anos: o rio nasce nas montanhas, formando os afluentes. Pode-se notar a presença de uma flor, de um pinheiro, das nuvens pesadas de chuva e do sol, que ainda parece brilhante. A explicação feita pela menina ao seu desenho: "Esta é uma paisagem local"

B) desenho de um menino de sete anos de idade: nuvens pesadas de chuva. Explicação dada pelo menino ao seu desenho: "A água sai das nuvens e as árvores da ilha".

Fonte: desenhos elaborados pelos estudantes. 


\section{A chuva como elemento principal e a fonte que alimenta os rios}

Esse tema, representado nos desenhos de 22 estudantes, refere-se à chuva como elemento principal no abastecimento de água dos rios: Os desenhos mostram que houve certo conhecimento da ligação entre o ciclo total de água como, por exemplo, a chuva como um fator chave e fonte de alimentação do rio. Nenhuma criança desenhou o rio em um ambiente urbano. Geralmente, os rios representados nos desenhos são longos e de grande fluxo, com nascente nas montanhas. Percebemos que os estudantes não retrataram os princípios de conservação, nem os mecanismos biológicos do ciclo da água e nenhuma forma de evaporação ou absorção de água pela terra. Isso deve estar relacionado à idade dos 22 participantes - cerca de $75 \%$ das crianças estavam com menos de 10 anos, idade em que é difícil dominar conceitos geográficos e ecológicos mais complexos - ou ao fato de estarem conscientes dos problemas ambientais.

Nesses desenhos, o armazenamento de água é representado através da presença de represas ou lagos. A chuva é abundante, colorida e acompanhada de trovões e relâmpagos. A ausência de grama e plantas foi evidenciada, o que pode ser explicado pelo momento em que os desenhos foram feitos, num período do ano, quando a seca estava bastante acentuada.

Figura 3. Desenhos e elementos representados

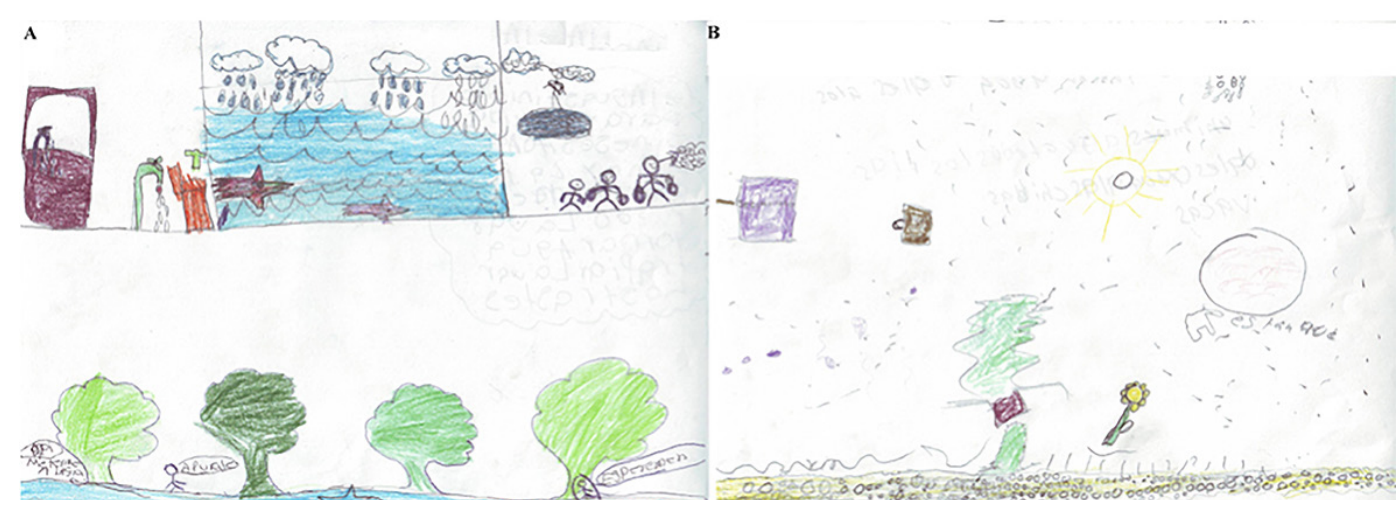

A) desenho de uma menina de 10 anos de idade: um tanque e duas torneiras. Chuvas abundantes que alimentam os rios. A tarefa de buscar água é representada abaixo e indivíduos que querem tomar banho na lagoa. A explicação dada pela menina ao seu desenho: A água é vida para mim. Eu posso beber, lavar a roupa e fazer outras coisas.

B) desenho de um menino de 11 anos, onde a torneira é representada, bem como uma lagoa com água potável para saciar a sede de um animal. A explicação dada pela criança ao seu desenho: Eu uso água para lavar, beber e para dar aos animais todos os dias.

Fonte: desenhos elaborados pelos estudantes. 


\section{A água como um recurso para atividades recreativas}

Apenas um pequeno número de desenhos representou as atividades recreativas associadas com água $(\mathrm{N}=6)$. Três dessas representações mostraram pequenos barcos à vela, um chuveiro, banho de chuva e dois rios em que as pessoas estavam nadando. Isso pode sugerir que atividades recreativas ligadas à água não são a realidade vivida por essas crianças. Elas têm uma quantidade limitada de tempo de lazer, uma vez que estão, geralmente, empenhadas nas tarefas domésticas e atividades produtivas, tais como ajudar os pais em atividades agrícolas nos campos ou na pecuária.

\section{A água como um recurso vital para as plantas, animais e homens}

Treze desenhos foram classificados nessa temática. A Figura 3B mostra um exemplo em que um animal está bebendo água. Uma menina de oito anos desenhou uma pessoa regando flores. Alguns dos desenhos expressam a importância da água para a biodiversidade local, como uma menina de nove anos aponta: "a água é importante para beber, tomar banho, lavar pratos e também é importante para os animais". Da mesma forma, um menino de 10 anos de idade afirma: "a água é muito importante para os animais, para as plantas e para os seres humanos."

\section{O consumo ideal de água na minha casa}

Rios ou barragens repletos de água para todas as atividades domésticas e para as plantas e os animais são representados nos desenhos de 22 crianças, revelando uma visão otimista: o desejo da disponibilidade de água para o futuro. Supõe-se que essas crianças desejam que as chuvas sejam frequentes. Elas não parecem ter ideias muito precisas sobre os reservatórios de água e também não representam técnicas de perfuração para a retirada de água do solo. Dois desenhos representam um grande reservatório de água, com torneiras do lado de fora da casa. Tanques enormes de plástico também são representados, pois é um sonho em comum conseguir dinheiro para a compra de água para o abastecimento de uma reserva para a família.

\section{Propostas para a aplicação do conhecimento científico indo ao encontro dos anseios dos estudantes de Francisco Medrano, México}

Problematizando o conhecimento construído pelos estudantes, verificando as contradições e localizando as limitações desse conhecimento, faremos aqui uma exposição de alternativas para que estas crianças/adolescentes possam apreender um conhecimento mais científico e cidadão em relação à problemática da água na região. Esta exposição não será feita de maneira exaustiva, pois as necessidades e anseios podem mudar com o passar do tempo.

Esta proposta busca a aproximação entre os pressupostos de Paulo Freire e do enfoque sobre as temáticas relacionadas à água e sua relevância social, envolvendo discussões além da água como elemento natural, presente no meio físico, mas a água como fonte de vida para homens, animais e plantas; um recurso distribuído de maneira desigual na região, no país e no mundo; a água que pode ser encontrada e armazenada através das tecnologias sociais e de políticas públicas voltadas para o abastecimento, fazendo uma "leitura do mundo" contemporâneo. 
Freire (1985) acreditava que "a leitura do mundo" precede sempre a leitura da palavra, precede, no sentido de vir antes e, principalmente, no sentido de ser mais importante. Ele acreditava que não tem nenhum sentido os educandos aprenderem a decodificar as sílabas de uma palavra sem compreender seu sentido social e político. Portanto, era preciso criar um "universo vocabular", gerando discussões sobre a realidade vivida. A palavra água é dotada desses sentidos, e os desenhos são instrumentos muito úteis na busca da compreensão cognitiva sobre o pré-tema gerador. Não falaremos aqui, nesta pesquisa, sobre um Tema-Gerador propriamente dito, pois não obedeceu rigorosamente a todos os momentos estudados por Paulo Freire e seus seguidores, descritos anteriormente e que valeria uma pesquisa mais aprofundada na região, utilizando este estudo como ponto de partida e subsídios para novos estudos na busca do Tema Gerador. O Quadro 1 mostra algumas sugestões para atividades relacionadas à água e que poderiam ser inseridas no currículo local.

Quadro 1. Pré-Temas-Geradores sobre a água, provenientes das representações dos estudantes de Francisco Medrano

\begin{tabular}{|l|l|l|l|}
\hline \multicolumn{1}{|c|}{$\begin{array}{c}\text { A água como } \\
\text { elemento natural }\end{array}$} & $\begin{array}{l}\text { Disciplinas que podem } \\
\text { trabalhar com a temática }\end{array}$ & $\begin{array}{c}\text { A água } \\
\text { como recurso }\end{array}$ & $\begin{array}{l}\text { Disciplinas que podem } \\
\text { trabalhar com a temática }\end{array}$ \\
\hline $\begin{array}{l}\text { Ciclos hidrológicos, } \\
\text { escassez hídrica e } \\
\text { estresse hídrico, } \\
\text { reservas naturais de } \\
\text { água, distribuição } \\
\text { de água no Planeta. }\end{array}$ & $\begin{array}{l}\text { Eiências, Geografia, } \\
\text { Ampanhol, Artes, Educação }\end{array}$ & $\begin{array}{l}\text { A importância } \\
\text { da água para a } \\
\text { biodiversidade do } \\
\text { Planeta: todas as } \\
\text { espécies de vida } \\
\text { necessitam de água } \\
\text { para sobreviver. }\end{array}$ & $\begin{array}{l}\text { Ciências, Geografia, } \\
\text { Espanhol, Artes, Educação } \\
\text { Ambiental, entre outras. }\end{array}$ \\
\hline $\begin{array}{l}\text { Evaporação ou } \\
\text { absorção de água. }\end{array}$ & $\begin{array}{l}\text { Ciências, Geografia, } \\
\text { Espanhol, Artes, Educação } \\
\text { Ambiental, entre outras. }\end{array}$ & $\begin{array}{l}\text { O homem como } \\
\text { modificador da } \\
\text { paisagem. }\end{array}$ & $\begin{array}{l}\text { Ciências, Geografia, } \\
\text { Espanhol, Artes, Educação } \\
\text { Ambiental, entre outras. }\end{array}$ \\
\hline $\begin{array}{l}\text { As diversas } \\
\text { paisagens segundo } \\
\text { a pluviosidade. }\end{array}$ & $\begin{array}{l}\text { Ciências, Geografia, } \\
\text { Espanhol, Artes, Educação } \\
\text { Ambiental, entre outras. }\end{array}$ & $\begin{array}{l}\text { Conservação da } \\
\text { água. }\end{array}$ & $\begin{array}{l}\text { Ciências, Geografia, } \\
\text { Espanhol, Artes, Educação } \\
\text { Ambiental, entre outras. }\end{array}$ \\
\hline $\begin{array}{l}\text { Os tipos de animais } \\
\text { e plantas segundo a } \\
\text { pluviosidade. }\end{array}$ & $\begin{array}{l}\text { Ciências, Geografia, } \\
\text { Espanhol, Artes, Educação } \\
\text { Ambiental, entre outras. }\end{array}$ & $\begin{array}{l}\text { Qualidade da água } \\
\text { e a questão de } \\
\text { saúde. }\end{array}$ & $\begin{array}{l}\text { Ciências, Geografia, } \\
\text { Espanhol, Artes, Educação } \\
\text { Ambiental, entre outras. }\end{array}$ \\
\hline Água e poder. & $\begin{array}{l}\text { Ciências, Geografia, } \\
\text { Espanhol, Artes, Educação } \\
\text { Ambiental, entre outras. }\end{array}$ \\
\hline
\end{tabular}

Fonte: elaborado pelas autoras. 
Sob o enfoque freiriano, os conceitos científicos foram selecionados a partir da necessidade dos estudantes quanto à compreensão de uma determinada situação que estão vivenciando. A configuração de currículos, na perspectiva de Abordagem Temática, consiste em uma forma de pensar e fazer o currículo de modo reflexivo e crítico, integrando teoria e prática, pesquisa e intervenção pedagógica.

\section{Considerações finais}

Os desenhos são, muitas vezes, utilizados para obter uma melhor ideia das concepções infantis sobre determinados temas. Este estudo analisou os diferentes conhecimentos sobre as representações de crianças residentes numa região rural semiárida do México a respeito da água. Essas representações podem ser úteis na busca de Temas Geradores, de Paulo Freire (1994).

Os 29 desenhos infantis analisados neste estudo sustentam a teoria e o modelo de Kellogg (1970), segundo o qual existe um padrão universal de desenvolvimento em arte infantil. Nosso estudo também apoia a teoria e alguns casos de Wales (1990), em que o autor afirma que a cultura é fundamental no desenvolvimento de representações simbólicas, como, por exemplo, a divisão das atividades relacionadas com a água entre meninos e meninas, verificadas nesta pesquisa.

Surgiram cinco principais temas representados através dos desenhos sobre a água: (i) a chuva como elemento principal e a fonte que alimenta os rios; (ii) a água como um recurso para o consumo doméstico; (iii) a água como um recurso para atividades recreativas; iv) a água como um recurso vital para plantas, animais e homens; e (v) o consumo ideal de água na minha casa.

Os desenhos fluem e sofrem influências através do conhecimento sobre a temática solicitada, que aqui é a água, através da idade e da capacidade de desenhar. Este estudo mostra o quanto o desenho foi importante para revelar as representações das crianças acerca do recurso natural água. Nossos resultados indicam ainda que desenhos de crianças podem ser usados para entender melhor a concepção que elas possuem sobre o meio ambiente e sobre os recursos naturais, mas é indispensável recorrer à explicação que elas dão ao seu desenho, por essa razão, a anotação com a explanação no verso é extremamente valiosa. Os desenhos infantis podem fornecer ricas informações sobre o desenvolvimento de percepções das crianças sobre o ambiente, que podem, efetivamente, ser utilizadas nas disciplinas de Geografia, Ciências e Educação Ambiental, voltadas para a educação no campo, na busca de conteúdos baseados nos anseios e necessidades desses jovens, em que a precariedade é evidenciada, em que as escolas são distantes e o único lugar onde encontram água para beber e se higienizar. São subsídios ricos para essas disciplinas e que custam tão pouco.

A análise das representações sociais dos estudantes do ensino fundamental de Taumalipas sobre o meio ambiente e sobre a água permite identificar as peculiaridades inerentes à população do campo em uma região semiárida. Na verdade, elementos importantes do ambiente 
humano (identidade, vida familiar, de ajuda mútua, tempo de lazer, etc.) e da importância da vida comunitária. Alguns valores, como o forte sentido de pertencimento e apego ao lugar também podem ser observados nessa população. Atuando no ambiente, representa a pedra angular sobre a qual o desenvolvimento de um modelo de intervenção educativa pode ser adaptado para esses estudantes específicos.

As representações sobre o meio ambiente dos estudantes do ensino primário em Taumalipas permitem o desenvolvimento de um modelo educacional que une o paradigma criativo, de Bertrand e Valois (1992), em que o ambiente é percebido como um objeto, um ambiente de aprendizagem e, sobretudo, como um local de ação. Esse modelo refere-se a um conjunto de atividades relacionadas à educação, realizadas por professores e estudantes, a fim de promover um processo gratificante de aprendizado, com o objetivo de favorecer uma relação harmoniosa com o meio ambiente local.

Os habitantes da província de Tamaulipas vivem com a realidade da falta de água, consequentemente, com a falta da abundância de alimentos e de uma vida mais tranquila, mas já estão conscientes de que a travessia da fronteira não é mais uma boa alternativa, por essa razão, é necessário valorizar o conhecimento tradicional e as riquezas culturais de seu povo. A escola que frequentam possui o necessário para as práticas educativas, e os professores se esforçam muito para valorizar o conhecimento tradicional, o que é visto através das exposições de peças arqueológicas por ali encontradas, do caderno de plantas locais, da pequena horta e do pomar feitos pelos estudantes, entre tantas outras atividades verificadas num curto espaço de tempo. Os professores esforçam-se muito para continuar a dinâmica do conhecimento empírico dos estudantes, da forma que são transmitidos, da maneira que usam os recursos naturais e do reforço do sistema de solidariedade e trocas de trabalhos. A cooperação e o amparo são também praticados com os que chegam à região, mesmo que por um curto período. Os nativos são capazes de dividir o pouco que possuem, sem restrições, bem como de ensinar sabiamente como utilizar a água de maneira bastante moderada. A generosidade é inerente a esse povo.

A escola deve também preparar os estudantes para o exercício da cidadania, quanto à participação pública nas questões relacionadas à água, para que participem das reuniões políticas locais, num estado cívico, social e democrático do direito da administração pública. É esse direito que deve incorporar a iniciativa e a criatividade dos cidadãos no processo de tomadas de decisões sobre a água. A promoção desse tipo de educação cívica é crucial. As pessoas precisam desenvolver prioridades locais e devem estar preparadas para agir em conjunto com as autoridades públicas na resolução dos problemas, dando início aos programas de ações, para cumprir o objetivo do desenvolvimento do Milênio relativo à água potável. Paulo Freire acreditava nas mudanças do ser humano, no agir em prol dos interesses locais, de maneira crítica, e na sua conscientização sobre a situação de exploração e dominação, diante dos segmentos mais altos da sociedade. 


\section{Referências}

ANTUNES, Â. Temas geradores. [S.1.]: Instituto Paulo Freire, [19--?]. (Cadernos de Formação). p. 82-88. Disponível em: < http://ead.unifreire.org/mod/resource/view. php?id=967 >. Acesso em: 5 jan. 2016.

ARRUDA, Â. Teoria das representações sociais e teorias de gênero. Cadernos de Pesquisa, São Paulo, n. 117, p. 127-147, 2002. Disponível em: < http://dx.doi.org/10.1590/S010015742002000300007>. Acesso em: 18 jun. 2016.

BARROS, F. G. N.; AMIN, M. M. Água: um bem econômico de valor para o Brasil e o mundo. Revista Brasileira de Gestão e Desenvolvimento Regional, Taubaté, v. 4, n. 1, p. 75-108, 2008.

BERTRAND, Y.; VALOIS, P. École et sociétés. Ottawa: Éditions Agence d'Arc, 1992.

BRUNI, J. C. A água e a vida. Tempo Social: revista de sociologia da USP, São Paulo, v. 5, n. 1/2, p. 53-65, 1993. Disponível em: <http://dx.doi.org/10.1590/ts.v5i1/2.84942>. Acesso em: 18 jun. 2016.

CARDOSO, J. S. A água como patrimônio comum da humanidade. Âmbito Jurídico, Rio Grande, v. 9, n. 30, jun. 2006. Disponível em: <http://www.ambito-juridico.com.br/site/ index.php?n_link=revista_artigos_leitura\&artigo_id=1184>. Acesso em: 6 jan. 2016.

CENTRE TRICONTINENTAL. L'eau, patrimoine commun de l'humanité. Louvain-la Neuve: L'Harmattan, 2001. (Alternatives Sud, v. 8).

CHANG, N. Children's drawings: science inquiry and beyond. Contemporary Issues in Early Childhood, v. 6, n. 1, p. 104-106, 2005.

COMITÊ PROMOTOR MUNDIAL PARA O CONTRATO DA ÁGUA. O manifesto da água: o direito de todos à vida. Lisboa, 1998. Disponível em: <http:/ /www.fmsoares.pt/ iniciativas/ilustra_iniciativas/1998/000342/>. Acesso em: 16 jan. 2016.

DE VANSSAY, B. Les représentations de l'eau. Vertigo : la revue électronique en sciences de l'environnement, Montréal, v. 4, n. 3, 2003. Disponível em : <https://vertigo.revues. org/1959\#quotation>. Acesso em : 18 jun. 2016.

FÉLONNEAU, M. L. Les représentations sociales dans le champ de l'environnement. In: MOSER, G.; WEISS, K. (Org.). Espaces de vie: aspects de la relation hommeenvironnement. Paris: Armand Colin, 2003. p. 145-176.

FORTES, H. Água: significados e simbologias na arte contemporânea. In: COLÓQUIO DE PSICOLOGIA DA ARTE, 2., 2007, São Paulo. Trabalhos... São Paulo: USP, 2007. Disponível em: <http://www.ip.usp.br/laboratorios/lapa/versaoportugues/2c91a.pdf>. Acesso em: 18 jun. 2016.

FREIRE, P. A importância do ato de ler. São Paulo: Cortez, 1985.

Pedagogia da autonomia. Rio de Janeiro: Paz e Terra, 2008.

Pedagogia do oprimido. Rio de Janeiro: Paz e Terra, 1994. 
GALIZONI, F. M.; RIBEIRO, E. M. Bem comum e normas costumeiras: a ética das águas em comunidades rurais de Minas Gerais. Ambiente \& Sociedade, São Paulo, v. 14, n. 1, p. 77-94, 2011. Disponível em: <http://dx.doi.org/10.1590/S1414-753X2011000100005>. Acesso em: 18 jun. 2016.

GARRIDO, L. S.; MEIRELLES, R. M. S. Percepção sobre meio ambiente por alunos das séries iniciais do ensino fundamental: considerações à luz de Marx e de Paulo Freire. Ciência \& Educação, Bauru, v. 20, n. 3, p. 671-685, 2014. Disponível em: <http://dx.doi. org/10.1590/1516-73132014000300010>. Acesso em: 18 jun. 2016.

GOLDBERG, L. G.; YUNES, M. A. M.; FREITAS, J. V. O desenho infantil na ótica da ecologia do desenvolvimento humano. Psicologia em Estudo, Maringá, v. 10, n. 1, p. 121-134, 2005. Disponível em: <http://www.scielo.br/pdf/pe/v10n1/v10n1a11>. Acesso em: 18 jun. 2016.

GONZÁLEZ-MEDRANO, F. Áreas protegidas de México: reserva de la biósfera El Cielo, Tamaulipas. [S.l.]: World Bank, 1993. (Internal report).

GRUBITS, S. A casa: cultura e sociedade na expressão do desenho infantil. Psicologia em Estudo, Maringá, v. 8, n. especial, p. 97-105, 2003. Disponível em: < http:// dx.doi. org/10.1590/S1413-73722003000300012>. Acesso em: 18 jun. 2016.

HAMMER, E. F. Aplicações clínicas dos desenhos projetivos. Rio de Janeiro: Interamericana, 1981.

JOVCHELOVITCH, S. Representações sociais: para uma fenomenologia dos saberes sociais, Psicologia e Sociedade, Belo Horizonte, v. 10, n. 1, p. 54-68, 1998.

KATZ, G. L. What can we learn from Reggio Emilia? In: EDWARDS, C.; GANDINI, L.; FORMAN, G. (Ed.). The hundred languages of children: the Reggio Emilia approach to early childhood education.Greenwich: Ablex, 1998. p. 19-40.

KELLOGG, R. Analysing children's art. Palo Alto: California National Press, 1970.

LOWENFELD, M. The work and aims of the Institute of Child Psychology. London: Institute of Child Psychology, 1977.

LUQUET, G. H. Le dessin enfantin. Paris: Félix Alcan, 1927. Disponível em:

$<$ http:/ / luquet-archives.univ-paris1.fr/document.php?domaine $=$ psychologie $\&$ fichier $=802$ \&photo=ledessinenfantin -005.jpg\&lg=fr>. Acesso em: 18 jun. 2016.

MARTINS, R. D. A. População e mudança climática: dimensões humanas das mudanças ambientais globais. Ambiente \& Sociedade, São Paulo, v. 1, n. 2, p. 22-43, 2009. Disponível em: <http://dx.doi.org/10.1590/S1414-753X2009000200014>. Acesso em: 18 jun. 2016.

MÉXICO. Instituto Nacional de Estadística y Geografia. México en cifras: Tamaulipas. Disponível em: <http://www3.inegi.org.mx/sistemas/mexicocifras $/$ default.aspx?e=28>. Acesso em: 1 abr. 2015.

OLIVEIRA, F. O.;WERBA, G. C. Representações sociais. In: JACQUES, M. G. C. et al. Psicologia social contemporânea: livro-texto. Petrópolis: Vozes, 1998. p. 104-117. 
PEDRINI, A.; COSTA, É. A.; GHILARDI, N. Percepção ambiental de crianças e préadolescentes em vulnerabilidade social para projetos de educação ambiental. Ciência \& Educação, Bauru, v. 16, n. 1, p. 163-179, 2010. Disponível em: < http://dx.doi. org/10.1590/S1516-73132010000100010>. Acesso em: 18 jun. 2016.

PIAGET, J.; INHELDER, B. La représentation de l'espace chez l'enfant. Paris: PUF, 1948.

PLAN municipal de desarrollo 2011-2013, del municipio de Tula, Tamaulipas. Periodico Oficial, Victoria, v. 136, anexo n. 39, 31 marzo 2011. Disponivel em: <http://poarchivo. tamaulipas.gob.mx/periodicos/2011/0311/pdf/Planes_Mpales/cxxxvi-39-310311-APLAN\%20MUNICIPAL-TULA.pdf>. Acesso em: 22 mar. 2016.

PROFICE, C. et al. Janelas para a percepção infantil de ambientes naturais. Psicologia em Estudo, Maringá, v. 18, n. 3, p. 529-539, 2013. Disponível em: < http://dx.doi.org/10.1590/ S1413-73722013000300014>. Acesso em: 18 jun. 2016.

RAMIREZ, M. F; YEPES, M. J. Geopolítica de los recursos estratégicos: conflictos por agua en América Latina. Revista de Relaciones Internacionales, Estrategia y Seguridad, Bogotá, v. 6, n. 1, p. 149-165, 2011. Disponível em: <http://www.redalyc.org/articulo. oa?id=92722560006>. Acesso em: 18 jun. 2016.

REBOUÇAS, A. C. Água na região Nordeste: desperdício e escassez. Estudos Avançados, São Paulo, v.11, n. 29, p. 127-154, 1997.

RIBEIRO, C. R.; PINTO JÚNIOR, A. A. A representação social da criança hospitalizada: um estudo por meio do procedimento de desenho-estória com tema. Revista da SBPH, Rio de Janeiro, v. 12, n. 1, p. 31-56, 2009. Disponível em: < http://pepsic.bvsalud.org/pdf/ rsbph/v12n1/v12n1a04.pdf>. Acesso em: 18 jun. 2016.

RUÍZ PÉREZ, V.; FERNÁNDEZ CRISPÍN, A. F. El agua para los niños de tercero de preescolar del municipio de Puebla, Pue. México. Forum de Sostenibilidad, Leioa, n. 2, p. 57-66, 2008. Disponível em: <http://www.ehu.eus/cdsea/web/images/pdf/Revista2. pdf>. Acesso em: 18 jun. 2016.

SCHWARZ, M. L. As representações de crianças e adolescentes da biodiversidade de Mata Atlântica na região de Joinville (Santa Catarina, Brasil). 2007, 275 f. Tese (Doutorado em Geografia) - Departamento de Geografia, Montreal, Universidade de Montréal, 2007.

SCHWARZ, M. L.; SEVEGNANI, L.; ANDRÉ, P. Representações da Mata Atlântica e de sua biodiversidade por meio dos desenhos infantis. Ciência \& Educação, Bauru, v. 13, n. 3 , p. 234-246, 2007. Disponível em: <http://dx.doi.org/10.1590/S1516-73132007000300007>. Acesso em: 18 jun. 2016.

SILVA, J. M. M. O desenho na expressão de sentimentos em crianças hospitalizadas. Fractal: revista de psicologia, Rio de Janeiro, v. 22, n. 2, p. 447-456, 2010. Disponível em: < http:// dx.doi.org/10.1590/S1984-02922010000800016>. Acesso em: 18 jun. 2016. 
SPINK, M.J.P. O estudo empírico das representações sociais. In: SPINK, M. J. P. (Org.). O conhecimento no cotidiano: as representações sociais na perspectiva da psicologia social. São Paulo: Brasiliense, 1993. p. 85-108.

WALES, R. Children's pictures. In: GRIEVE, R.; HUGHES, M. Understanding children. Oxford, UK : Basil Blackwell, 1990. p. 140-155. 